\title{
Antimicrobial Peptides: New Recognition Molecules for Detecting Botulinum Toxins
}

\author{
Nadezhda V. Kulagina, George P. Anderson, Frances S. Ligler, Kara M. Shaffer and \\ Chris Rowe Taitt *
}

Center for Bio/Molecular Science \& Engineering, Code 6900, Naval Research Laboratory, 4555 Overlook Ave. SW, Washington, DC 20375, USA

* Author to whom correspondence should be addressed. E-Mail: chris.taitt@nrl.navy.mil Received: 24 October 2007 / Accepted: 14 November 2007 / Published: 16 November 2007

\begin{abstract}
Many organisms secrete antimicrobial peptides (AMPs) for protection against harmful microbes. The present study describes detection of botulinum neurotoxoids A, B and $\mathrm{E}$ using AMPs as recognition elements in an array biosensor. While AMP affinities were similar to those for anti-botulinum antibodies, differences in binding patterns were observed and can potentially be used for identification of toxoid serotype. Furthermore, some AMPs also demonstrated superior detection sensitivity compared to antibodies: toxoid A could be detected at $3.5 \mathrm{LD}_{50}$ of the active toxin in a 75-min assay, whereas toxoids $\mathrm{B}$ and E were detected at 14 and $80 \mathrm{LD}_{50}$ for their respective toxins.
\end{abstract}

Keywords: Antimicrobial peptide, botulinum toxin, detection, array, biosensor

\section{Introduction}

Botulism is the clinical term for the neuroparalytic disease caused by one of several protein toxins produced by Clostridium botulinum. In spite of its relatively low rate of incidence, foodborne botulism is still considered a public health emergency due to its high mortality rate and the potential for widespread ingestion of contaminated foodstuffs [1]. The mortality rate has decreased to approximately $15 \%$ in the last 50 years [2] — primarily due to improvements in supportive and respiratory care and to administration of antitoxin in the early stage of illness [3]. In spite of these 
improvements, the high lethality of these toxins has served as an inducement for nefarious activities, as evidenced by state-sponsored programs for their weaponization and two intentional releases of the toxins by the Aum Shinrikyo cult [4].

The neurotoxins produced by $C$. botulinum exist as structurally similar but antigenically distinct serotypes. Each toxin is synthesized as a $150 \mathrm{kDa}$ polypeptide that is activated by proteolysis and selective reduction, yielding a heavy chain $(\mathrm{H}, 100 \mathrm{kDa})$ and a light chain $(\mathrm{L}, 50 \mathrm{kDa})$ linked by an interchain disulfide. Regions of sequence homology suggest that all serotypes employ similar modes of action in neurotoxicity. The $\mathrm{H}$ chains provide cholinergic specificity. The $\mathrm{L}$ chains are zinc endopeptidases that cleave the SNARE proteins found in the presynaptic junction of neuronal cells at toxin-specific loci; cleavage of any of these SNARE proteins prevents release of acetylcholine, resulting in blockage of motor nerve terminals and flaccid paralysis. Botulinum neurotoxins are the most potent biological toxins in the world $[5,6]$. By extrapolation from primate studies, the lethal amount of neurotoxin A toxin for a 70-kg human would be approximately 0.09-0.15 $\mu \mathrm{g}$ delivered intravenously or intramuscularly, $0.70-0.90 \mu \mathrm{g}$ delivered by inhalation, and $70 \mu \mathrm{g}$ taken orally [5].

The only currently approved test for laboratory confirmation of botulism and identification of a source food is the mouse bioassay, which can detect as little as $10 \mathrm{pg}$ of neurotoxin [7, 8]. However, bioassays require a high level of animal use (at least four animals per sample if serotyping is desired), a long time for definitive results (up to 4 days), and shipment of suspect samples to an appropriate testing facility. There are several ELISA-based assays that have been validated for toxin detection in cell cultures with detection limits in the low $\mathrm{pg} / \mathrm{ml}$ range [9]. Other methods with sensitivities comparable to mouse bioassays have been described, but many are limited by assay complexity, reagent expense, and the requirement for multiple lengthy incubations and/or expensive instrumentation to achieve suitable sensitivities [10-15]. For these reasons, a rapid, sensitive, and easy-to-use test for botulinum toxins requiring only standard laboratory equipment would be highly advantageous for both patient treatment and timely public health response.

With the objective of creating a platform to detect many different organisms without target-specific reagents, we have recently evaluated arrays of antimicrobial peptides (AMPs) as alternative recognition molecules; these arrays were capable of detecting and discriminating between multiple bacteria and rickettsiae based on the patterns of binding [16-18]. Many AMPs exert their antimicrobial activity by interacting with invariant components of microbial surfaces and disrupting cell membranes [19-21]. Although current dogma holds that the natural targets of most AMPs are bacteria, fungi, and enveloped viruses, we have determined that some of these peptides also bind to toxins. In this study, we describe an AMP-based assay for inactivated botulinum toxins A, B and E. Several AMPs demonstrated superior detection capabilities when compared to simultaneous, parallel assays on the same instrument using antibodies for target capture. Although binding by AMPs was semi-selective, these assays were able to discriminate between neurotoxoids A and B based on patterns of binding. Kinetic and affinity constants for binding of inactivated botulinum neurotoxins A, B, and E to immobilized AMPs were also determined. 


\section{Results and Discussion}

It is widely held that the natural mechanistic targets for the microbiocidal activity of many AMPs are cellular membranous structures; a large body of work describes the theory and practical aspects of AMP-membrane interactions [19-23]. It was therefore surprising when Garcia and colleagues found that the AMP buforin-I (Table 1) inhibited the protease activity of botulinum neurotoxin B in solution [24]. In large part because of Garcia's original observations and subsequent work [25, 26], we attempted to assess the potential of a number of other AMPs unrelated to buforins to detect inactivated botulinum toxins $\mathrm{A}, \mathrm{B}$, and $\mathrm{E}$ in rapid assays.

Table 1. Amino acid sequences of relevant AMPs and those used in this study.

\begin{tabular}{l|ll}
\hline $\begin{array}{l}\text { Polymyxin B } \\
\text { Polymyxin E }\end{array}$ & fa-BTBBBFLBBT & fa=fatty acid; B=diaminobutyrate \\
$\begin{array}{l}\text { Polymyxin B } \\
\text { nonapeptide }\end{array}$ & fa-BTBBBFLBBT & B= diaminobutyrate \\
Buforin-I & AGRGKQGGKVRAKAKTRSSRAGLQFPVGRVHRLLRKGNK \\
Buforin-II & TRSSRAGLQFPVGRVHRLLRK \\
Melittin & GIGAVLKVLTTGLPALISWIKRKRQQ-CONH 2 \\
Cecropin A & KWKLFKKIEKVGQNIRDGIIKAGPAVAVVGQATQIAK-CONH 2 \\
Cecropin B & KWKVFKKIEKMGRNIRNGIVKAGPAIAVLGEAKAL \\
Cecropin P1 & SWLSKTAKKLENSAKKRISEGIAIAIQGGPR \\
Bactenecin & RLCRIVVIRVCR \\
Magainin-1 & GIGKFLHSAGKFGKAFVGEIMKS \\
Parasin & KGRGKQGGKVRAKAKTRSS \\
\hline
\end{tabular}

Note: amino acid sequences cleaved by peptidase activity of botulinum neurotoxins A, B, and E (QF, KR, RI) are bolded.

As a first step in creating a multiplexed AMP-based screening system, different AMPs (Table 1) were immobilized in arrays on silane-modified microscope slides using direct covalent attachment [17]. Solutions containing inactivated botulinum toxins A and B were incubated with the patterned surfaces and bound toxoids were detected using a fluorophore-labeled antibody directed against toxins A and B (Fig. 1a). For kinetic analyses, toxoids A, B, and E were labeled with fluorescent dye and binding of toxoids to immobilized AMPs was measured directly, in real-time. 

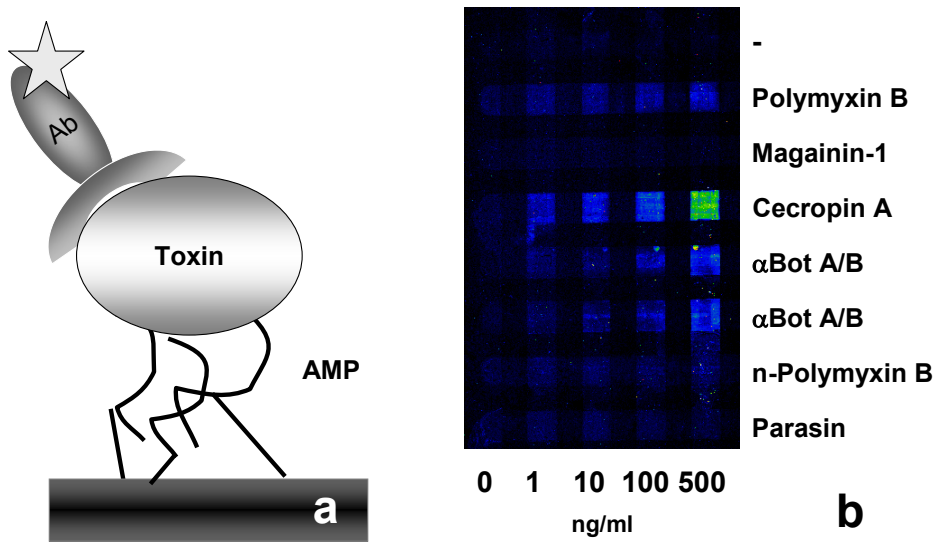

Figure 1. Sandwich assays for botulinum toxoids using immobilized AMPs. Panel a: Schematic of sandwich-format assay for inactivated botulinum toxins. Anti-botulinum toxin antibody $(\mathrm{Ab})$ is shown labeled with a fluorophore $(\star)$. Panel b: Representative image of AMP-capture sandwich format assay for inactivated botulinum neurotoxin A. Cecropin A demonstrates high affinity for the toxin with a detection limit below $1 \mathrm{ng} / \mathrm{ml}$; the detection limit for control antibodies ( $\alpha$ Bot A/B) was 10 $\mathrm{ng} / \mathrm{ml}$. No significant binding was observed in the negative control lane (-) or in the buffer blanks.

Fig. $1 \mathrm{~b}$ shows a representative image of a patterned array of AMPs used to detect botulinum toxoid $\mathrm{A}$ in a 75-min "sandwich" format assay using a fluorescent antibody tracer to detect bound toxoid. Dose-response curves were generated for binding of toxoids A and B to the immobilized peptides (Fig. 2 ). Detection limits were then determined as the lowest concentrations tested with mean net signals ( $\mathrm{n}$ $\geq 3$ separate array elements) at least 3 standard deviations above the mean of negative controls (buffer blanks) and are shown in Table 2.
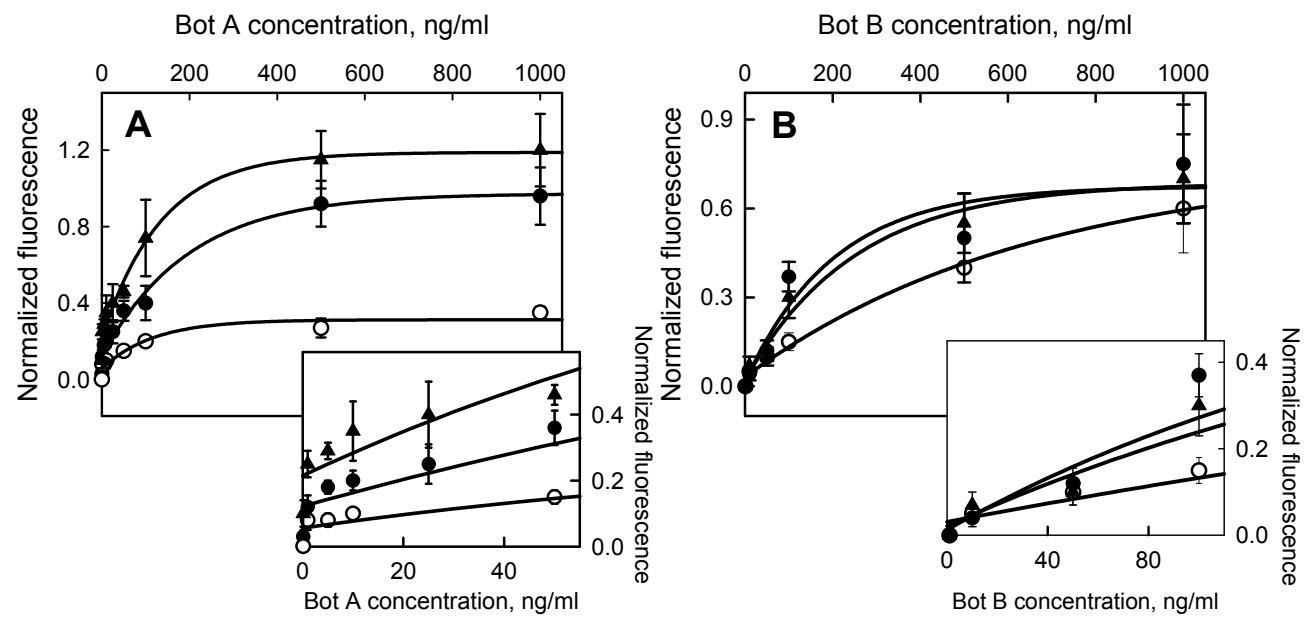

Figure 2. Dose response curves for botulinum toxoids A (a) and B (b) in sandwich format assays. Shown are binding of inactivated toxins to polymyxin B $(O)$, cecropin $A(\boldsymbol{\Delta})$, and anti-botulinum toxin $\mathrm{A} / \mathrm{B}(\bullet)$. Data shown were normalized with respect to chicken positive control signals to account variability between the slides. Error bars represent standard deviations ( $\mathrm{n} \geq 4$ replicate spots). 
Table 2. Detection limits for inactivated toxins in "sandwich" assays.

\begin{tabular}{ccc}
\hline Immobilized biomolecule & Inactivated botulinum toxin A & Inactivated botulinum toxin A \\
\hline Anti-botulinum toxin A/B & $10 \mathrm{ng} / \mathrm{ml}$ & $50 \mathrm{ng} / \mathrm{ml}$ \\
Polymyxin B & $10 \mathrm{ng} / \mathrm{ml}$ & $50 \mathrm{ng} / \mathrm{ml}$ \\
Polymyxin B nonapeptide & $>1 \mu \mathrm{g} / \mathrm{ml}$ & $\mathrm{n} . \mathrm{d} . *$ \\
Polymyxin E & $25 \mathrm{ng} / \mathrm{ml}$ & $50 \mathrm{ng} / \mathrm{ml}$ \\
Magainin-1 & $>1 \mu \mathrm{g} / \mathrm{ml}$ & $>1 \mu \mathrm{g} / \mathrm{ml}$ \\
Parasin & $>1 \mu \mathrm{g} / \mathrm{ml}$ & $>1 \mu \mathrm{g} / \mathrm{ml}$ \\
Buforin-II & $10 \mathrm{ng} / \mathrm{ml}$ & $\mathrm{n} . \mathrm{d}$. \\
Cecropin A & $1 \mathrm{ng} / \mathrm{ml}$ & $50 \mathrm{ng} / \mathrm{ml}$ \\
Cecropin B & $5 \mathrm{ng} / \mathrm{ml}$ & $50 \mathrm{ng} / \mathrm{ml}$ \\
Cecropin P1 & $>1 \mu \mathrm{g} / \mathrm{ml}$ & $>1 \mu \mathrm{g} / \mathrm{ml}$ \\
Melittin & $5 \mathrm{ng} / \mathrm{ml}$ & $10 \mathrm{ng} / \mathrm{ml}$ \\
Bactenecin & $5 \mathrm{ng} / \mathrm{ml}$ & $50 \mathrm{ng} / \mathrm{ml}$ \\
\hline
\end{tabular}

*not determined

In general, detection limits were lower for toxoid $\mathrm{A}$ than toxoid $\mathrm{B}$, in large part due to the higher degree of tracer antibody binding to toxoid A (compare antibody lanes for the two serotypes in Fig. 3a). Both toxoids were detectable at LODs that are consistent with previous immunoassay results using the same system [27, 28]. LODs similar to those of the antibody controls were obtained with immobilized polymyxins $\mathrm{B}$ and $\mathrm{E}$, which differ by a single amino acid. Interestingly, however, toxoid A did not bind to polymyxin B nonapeptide, which is identical to polymyxin B but lacks the fatty acyl tail. Neither toxoid bound significantly to magainin-1. Sensitivity for botulinum toxoid A detection was significantly enhanced using cecropin $A$ as the immobilized recognition species; the LOD determined for toxoid A binding to cecropin A was $1 \mathrm{ng} / \mathrm{ml}\left(3.5 \mathrm{LD}_{50}\right)$, although samples containing lower concentrations occasionally gave signals above those of negative control $(P<0.05)$ (Fig. 2a). Detection of botulinum toxoid B was most sensitive with immobilized melittin, with an LOD of 10 $\mathrm{ng} / \mathrm{ml}\left(14 \mathrm{LD}_{50}\right)$.

Although the buforin-I originally used in Garcia's inhibition studies is no longer commercially available, we were able to test parasin and buforin-II, two peptides analogous to the $\mathrm{N}$ - and C-terminal portions of buforin-I, respectively. While buforin-II bound toxoid A, giving a detection limit of 10 $\mathrm{ng} / \mathrm{ml}$, parasin failed to bind either of the inactivated toxins at all concentrations tested (up to $1 \mu \mathrm{g} / \mathrm{ml}$. As previously observed with all other bacteria and viruses tested [16-18], a high surface density was required for optimal binding of both toxoids to immobilized AMPs (Fig. 3a, 3b, additional data not shown), whereas maximal binding to immobilized antibodies was not as greatly affected. The unexpected differences in density effects cannot be not explained by molecular size. Rather, the high surface density of immobilized AMPs may have endowed these surfaces with sufficient avidity to detect bacterial targets at lower concentrations. Furthermore, peptide-peptide interactions have been postulated to be required for strong target binding and microbicidal activity [29-32]. 

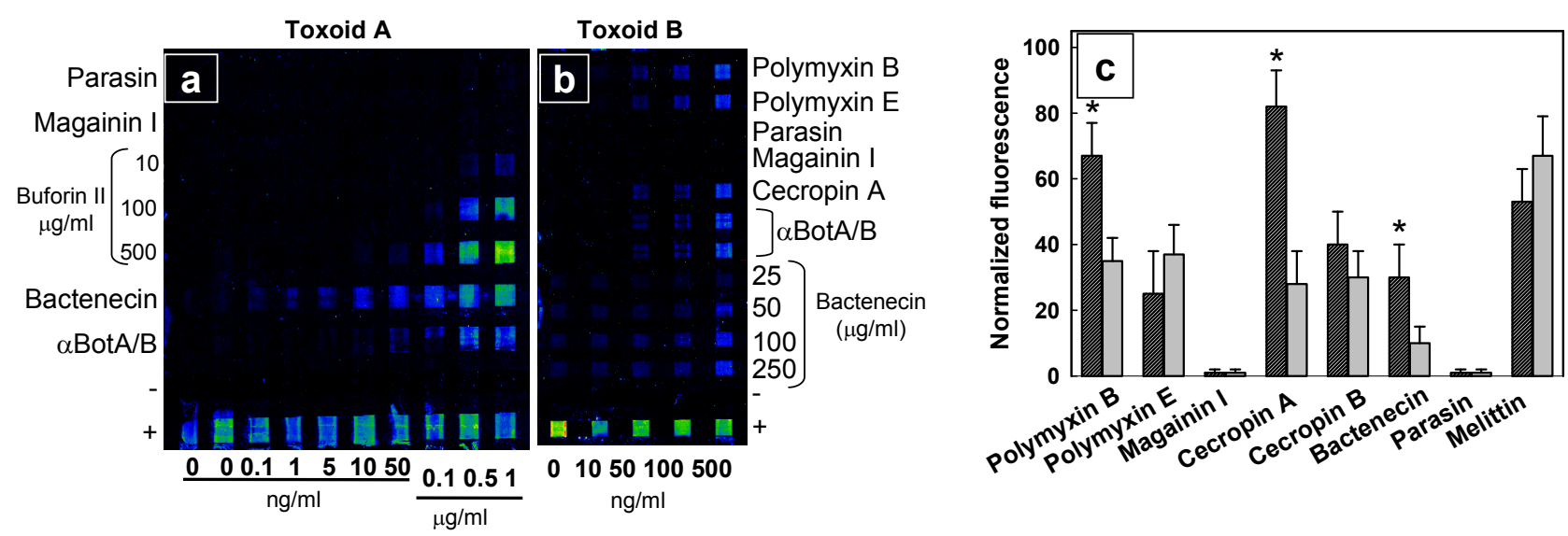

Figure 3. Representative images of AMP-capture sandwich assays for inactivated botulinum toxin A (a) and B (b); note the effect of increasing concentrations of patterned AMPs (buforin II in panel a, bactenecin in panel b). Negative control lanes (-) were patterned with buffer, whereas positive control lanes $(+)$ were patterned with anti-chicken IgY and interrogated with Cy3-chicken IgY. Panel c shows binding patterns of $100 \mathrm{ng} / \mathrm{ml}$ inactive botulinum neurotoxins A (striped bars) and B (gray bars) to immobilized AMPs, with fluorescent intensities normalized with respect to chicken positive control signals to account for variability between slides. * indicates a statistical difference $(\mathrm{P}<0.05)$. Error bars represent standard deviations ( $\mathrm{n} \geq 4$ replicate array elements).

In spite of obvious similarities in AMP binding, various AMPs demonstrated some significant differences in binding the inactivated neurotoxins $\mathrm{A}$ and $\mathrm{B}$ in sandwich assays $(\mathrm{P}<0.05$, analysis of covariance for linear portions of the dose-response curves). For clarity, these differences are shown in Fig. $3 \mathrm{c}$ at a single concentration $(100 \mathrm{ng} / \mathrm{ml})$ and normalized to the positive control (chicken $\mathrm{IgY}$; * indicates $\mathrm{P}<0.05$, student's t-test). Although binding of target to a single immobilized AMP will not allow unequivocal identification, the patterns of binding to multiple peptides can potentially be used to identify which serotype is present with use of an appropriate pattern recognition algorithm. Although dual-toxin-producing strains have been identified [33,34], the vast majority of $C$. botulinum strains produce only a single toxin serotype [35], thereby simplifying pattern recognition by minimizing the potential for toxin mixtures.

A series of real-time binding experiments were performed to determine the kinetics of interactions between the inactive toxins and immobilized AMPs. Toxoids A, B and E were labeled with fluorophore and direct format assays were performed (Fig. 4a). Since this format does not require use of a fluorescent tracer antibody, direct monitoring of binding of the labeled toxoids to immobilized AMPs was possible. Furthermore, this format allowed binding of inactive botulinum toxin E to AMPs to be assessed; antibodies with sufficient affinity to this serotype were not available to use as "tracer" antibodies in "sandwich" assays (cf. Fig. 1a). Fig. 4b shows concentration-dependent binding of labeled toxoid E to melittin and cecropins A and B. Direct assay LODs for binding of inactivated botulinum toxin $\mathrm{E}$ to melittin, polymyxin $\mathrm{B}$ and polymyxin $\mathrm{E}$ were $25 \mathrm{ng} / \mathrm{ml}\left(75 \mathrm{LD}_{50}\right)$, and $50 \mathrm{ng} / \mathrm{ml}$ $\left(150 \mathrm{LD}_{50}\right)$ for binding to bactenecin and cecropins $\mathrm{A}$ and $\mathrm{B}$. None of the labeled toxoids bound to immobilized magainin-1 or parasin. 

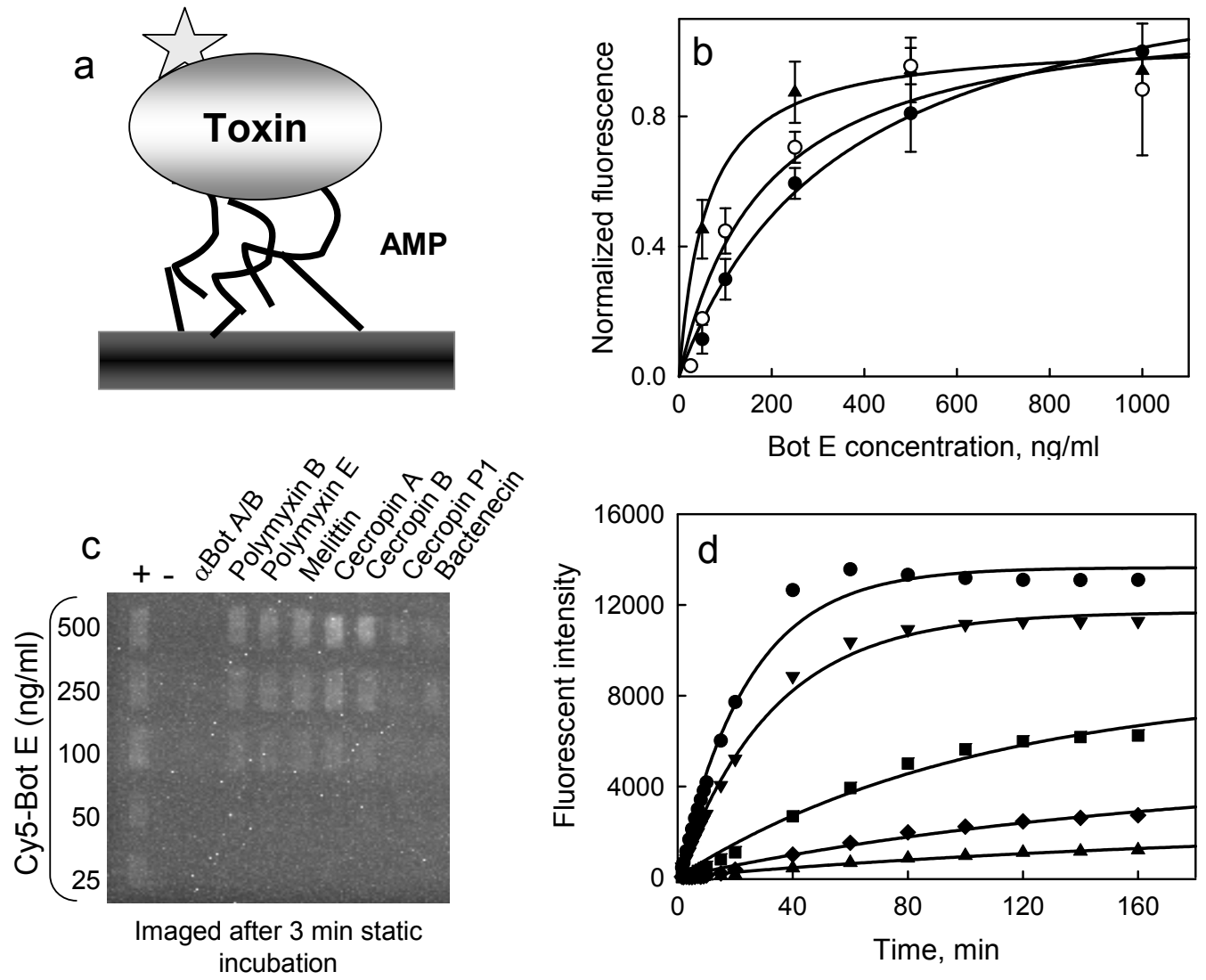

Figure 4. Direct assays for botulinum toxoids using immobilized AMPs. Panel a: Schematic of direct assay used for kinetic determination; the toxin is shown labeled with fluorophore ( $\star)$. Panel b: Doseresponse curve of Cy5-labeled inactivated neurotoxin E binding to immobilized cecropin $\mathrm{A}(\boldsymbol{\Delta})$, cecropin B (•), and melittin (०). Error bars represent standard deviations ( $\mathrm{n} \geq 4$ replicate array elements). Panel c: Representative image of labeled inactivated botulinum toxin E binding to an array patterned with multiple AMPs (toxoid concentrations shown to the left of the image). This image was

taken 3 minutes after addition of the labeled toxoid and shows that binding of toxin occurs very rapidly. Panel d: Representative timecourse curves of various concentrations of labeled toxoid $\mathrm{E}$ binding to cecropin B; data were extracted from images taken at different incubation times (such as that shown in panel c). Shown are $1000 \mathrm{ng} / \mathrm{ml}(\bullet), 500 \mathrm{ng} / \mathrm{ml}(\boldsymbol{\nabla}), 250 \mathrm{ng} / \mathrm{ml}(\boldsymbol{\nabla})$, $100 \mathrm{ng} / \mathrm{ml}(\diamond)$, and $50 \mathrm{ng} / \mathrm{ml}(\boldsymbol{\Delta})$ toxoid E.

Binding of labeled toxoids A, B, and E to the immobilized AMPs was followed in real-time, a timedependence curve was generated at each concentration of the toxoids (Figs. 4c, 4d), and the kinetic and dissociation constants determined. The toxoids bound with high affinity to the immobilized AMPs, with nanomolar to sub-nanomolar $\mathrm{K}_{d} \mathrm{~s}$ (Table 3). In general, differences in kinetic or dissociation constants were not significant $(\mathrm{P}>0.05)$. This general trend was primarily due to the large standard deviations observed in both $k_{\text {on }}$ and $k_{\text {off }}$, used to calculate the $K_{d} s$; coefficients of variation for the kinetic constants ranged from 4 to $68 \%$, due to between-slide variability, but were generally lower than those calculated for the $K_{d} s$. The differences observed in sandwich assay results $(P<0.05$; Figure $3 c)$ presumably reflect variations in the $\mathrm{k}_{\text {off }}$ rates. The sandwich assays had several wash steps, performed under flow, as well as an additional incubation step; we have previously observed that higher 
sensitivities were obtained when samples were incubated static (versus under flow) in both direct and sandwich assay formats (data not shown). This effect has also been observed for other targets binding to AMPs [17].

Table 3. Kinetic and dissociation constants for binding of inactivated botulinum toxins $\mathrm{A}, \mathrm{B}$, and $\mathrm{E}$ to immobilized AMPs

\begin{tabular}{|c|c|c|c|c|c|c|c|c|c|}
\hline \multirow[b]{2}{*}{$\begin{array}{l}\text { Capture } \\
\text { molecule }\end{array}$} & \multicolumn{3}{|c|}{ Inactivated botulinum toxin $\mathrm{A}$} & \multicolumn{3}{|c|}{ Inactivated botulinum toxin $B$} & \multicolumn{3}{|c|}{ Inactivated botulinum toxin $\mathrm{E}$} \\
\hline & $\mathrm{K}_{\mathrm{d}}(\mathrm{nM})$ & $\begin{array}{l}\mathrm{k}_{\mathrm{on}}\left(\mathrm{M}^{-1} \mathrm{~s}^{-1}\right) \\
\times 10^{4}\end{array}$ & $\begin{array}{l}\mathrm{k}_{\mathrm{off}}\left(\mathrm{s}^{-1}\right) \\
\times 10^{-4}\end{array}$ & $\mathrm{~K}_{\mathrm{d}}(\mathrm{nM})$ & $\begin{array}{l}\mathrm{k}_{\text {on }}\left(\mathrm{M}^{-1} \mathrm{~s}^{-1}\right) \\
\times 10^{4}\end{array}$ & $\begin{array}{l}\mathrm{k}_{\mathrm{off}}\left(\mathrm{s}^{-1}\right) \\
\times 10^{-4}\end{array}$ & $\mathrm{~K}_{\mathrm{d}}(\mathrm{nM})$ & $\begin{array}{l}\mathrm{k}_{\text {on }}\left(\mathrm{M}^{-1} \mathrm{~s}^{-1}\right) \\
\times 10^{4}\end{array}$ & $\begin{array}{l}\mathrm{k}_{\mathrm{off}}\left(\mathrm{s}^{-1}\right) \\
\times 10^{-4}\end{array}$ \\
\hline Antibody & $2.6 \pm 0.6$ & $8.3 \pm 1.6$ & $2.2 \pm 0.5$ & $4.8 \pm 1.7$ & $2.3 \pm 0.6$ & $1.1 \pm 0.2$ & $\mathrm{n} / \mathrm{a}$ & $\mathrm{n} / \mathrm{a}$ & $\mathrm{n} / \mathrm{a}$ \\
\hline Polymyxin B & $7.5 \pm 0.4$ & $6.7 \pm 0.3$ & $5.0 \pm 1.0$ & $3.2 \pm 2.0$ & $6.7 \pm 3.1$ & $2.2 \pm 0.9$ & $12.3 \pm 8.1$ & $2.8 \pm 1.8$ & $3.5 \pm 0.6$ \\
\hline Polymyxin E & $13.4 \pm 6.8$ & $3.1 \pm 1.4$ & $4.2 \pm 0.5$ & $5.2 \pm 3.0$ & $4.1 \pm 2.1$ & $2.2 \pm 0.6$ & $12.9 \pm 8.5$ & $2.8 \pm 1.8$ & $3.7 \pm 0.7$ \\
\hline Cecropin A & nd & nd & nd & $7.3 \pm 3.4$ & $2.3 \pm 1.0$ & $1.7 \pm 0.3$ & $0.11 \pm 0.02$ & $28.4 \pm 5.4$ & $0.32 \pm 0.02$ \\
\hline Cecropin B & $2.5 \pm 0.8$ & $11.9 \pm 2.3$ & $3.0 \pm 0.7$ & $6.5 \pm 2.7$ & $3.4 \pm 1.0$ & $2.2 \pm 0.6$ & $1.9 \pm 1.7$ & $6.2 \pm 2.1$ & $1.2 \pm 0.5$ \\
\hline Cecropin P1 & $6.9 \pm 2.5$ & $3.9 \pm 1.3$ & $2.7 \pm 0.4$ & $16.1 \pm 7.6$ & $1.3 \pm 0.6$ & $2.2 \pm 0.4$ & $18.4 \pm 5.0$ & $1.5 \pm 0.4$ & $2.7 \pm 0.1$ \\
\hline Melittin & $9.7 \pm 5.3$ & $2.8 \pm 1.4$ & $2.7 \pm 0.5$ & $4.2 \pm 1.7$ & $4.4 \pm 1.4$ & $1.8 \pm 0.5$ & $2.5 \pm 1.5$ & $8.0 \pm 2.8$ & $2.0 \pm 0.9$ \\
\hline Bactenecin & $3.3 \pm 1.2$ & $8.0 \pm 2.5$ & $2.7 \pm 0.4$ & $5.0 \pm 3.4$ & $4.7 \pm 2.6$ & $2.3 \pm 0.9$ & $6.1 \pm 1.6$ & $4.4 \pm 1.1$ & $2.7 \pm 0.2$ \\
\hline
\end{tabular}

$\mathrm{n} / \mathrm{a}$ - Due to unavailability of antibody against botulinum $\mathrm{E}$ toxin, kinetics parameters were not determined for this toxoid. nd - Cy5-labeled inactivated botulinum A toxin did not bind to immobilized cecropin A.

In the direct assays, several instances of significantly different affinity and kinetic values in the direct assays were noted. A higher $\mathrm{k}_{\text {on }}$ was observed for toxoid A binding to cecropin $\mathrm{B}(\mathrm{P}<0.05)$, but this was offset by a slightly higher $\mathrm{k}_{\text {off }}$, leading to a $\mathrm{K}_{\mathrm{d}}$ similar to those from the other AMPs $(\mathrm{P}>$ 0.05). A second notable exception was the inability of fluorescently labeled toxoid $\mathrm{A}$ to bind to cecropin A, shown to have the highest binding activity in sandwich assays. Since binding to other AMPs did not appear affected, it is possible that the mechanism of this interaction differs from those of the other AMPs. On the other hand, cecropin A had the highest affinity for labeled toxoid $\mathrm{E}$; its $\mathrm{K}_{\mathrm{d}}$ $\left(10^{-10} \mathrm{M}\right)$ was at least ten-fold lower than all others measured and was due to both significantly higher $\mathrm{k}_{\text {on }}$ and lower $\mathrm{k}_{\text {off }}$ rates when compared to other AMPs and the other toxins $(\mathrm{P}<0.01)$. These $\mathrm{K}_{d} \mathrm{~S}$ were significantly lower than the $\mathrm{IC}_{50} \mathrm{~s}$ measured for buforin-II and botulinum toxin $\mathrm{B}$ in inhibition assays $[24,25]$, as well as the inhibition or Michaelis constants of other peptide substrate analogs and inhibitors of botulinum neurotoxins [36-40]. However, a number of peptide inhibitors with nanomolar dissociation constants have recently been developed [41].

In their initial 1999 report and subsequent work [24-26], Garcia's group obtained data to support the hypothesis that buforins, previns, and related AMPs inhibit botulinum neurotoxin B by interacting with the proteolytic active site. These interactions were postulated to require an $\alpha$-helical stretch upstream of the cleavage site, a helix-turn-helix or extended helix motif, and the QF cleavage sequence of its native substrate, VAMP-2 [42]. By analogy, inhibitors of botulinum neurotoxins A and E using a similar inhibitory mechanism would require the appropriate $\mathrm{QR} / \mathrm{KR}$ and $\mathrm{RI}$ cleavage sequences from SNAP-25, respectively $[43,44]$. In contrast, the present study demonstrates interaction of inactivated 
neurotoxins with a number of AMPs that do not possess the appropriate cleavage sites for the neurotoxins tested (Table 1); cleavage sites are found in only buforin-II (QF), melittin (KR), and bactenecin (RI). More recently, others have demonstrated the importance of a hinge region for binding and inhibition of botulinum neurotoxins by combinatorially-derived peptides $[45,46]$. Several of the AMPs that interacted with the toxoids (polymyxins, bactenecin) clearly do not form the requisite extended $\alpha$-helical or helix-turn-helix motifs. However, the majority of the $\alpha$-helical AMPs showing high binding to the toxoids possess a helix-breaking proline, while those with minimal binding (magainin-1, parasin) do not.

Exosites have recently been confirmed by crystallographic evidence as sites of substrate interaction remote from the active site [47-49]. These exosites are hypothesized to be responsible for specificity and may require specific chemical and structural motifs (SNARE sequences) for target recognition [50-53]. In spite of the tremendous sequence conservation of SNARE sequences among target proteins, none of the AMPs tested in this study possess the requisite numbers of acidic, hydrophobic and polar residues with the appropriate positioning $[50,53]$. Other sites of toxin-ligand interactions have also been described [54]. The preparations used in the current study were derived from neurotoxin complexes, rather than individual purified toxins. The neurotoxin associated proteins (NAPs) within the complexes protect the neurotoxins from proteases, heat, and acidity within the gut [55-57] and may be responsible for mediating interactions with the immobilized AMPs. Although future experiments with purified toxins will indicate whether binding is mediated by the toxin or by associated proteins, it is clear that the naturally secreted, complexed forms interact with AMPs.

While not yet eliminating the need for an immunological component, the AMP-based assays developed here (AMP capture, antibody tracer) demonstrated the potential for simple and rapid $(<75$ min) detection of inactivated botulinum neurotoxins; only standard laboratory instruments (peristaltic pump, microarray reader) were required. When using the optimal AMPs for target capture, assays for the toxoids were more sensitive than immunoassays previously developed on the same instrument and those performed in parallel [Table 2; 27, 28].

Although the detection limits were also in the same range as a number of other rapid fluorimetric or colorimetric immunoassays [58-64], they are still not sufficient to detect levels comparable to mouse bioassays (pg/ml levels). The AMP-based assays described in this study were also significantly less sensitive than several recently described assays using hydrolysable peptide substrates; LODs for these latter assays are in the low to sub-pg/ml ranges, with cleavage products detected using capillary electrophoresis, atomic force microscopy, mass spectrometry, or fluorescence $[11,13,14,65,66]$. These activity-based assays have the additional advantage of serotype discrimination and determination of toxin functionality (versus immunogenicity). However, a limitation to these substrate-based assays is the potential for peptide degradation by endogenous proteases, which may result in false-positive results if cleavage products are not individually characterized. Although the effect of clinical or food matrices on binding and stability of the immobilized AMPs was not addressed in the present study, temperature, salt, and proteolytic stability of some AMPs has been documented $[17,19,23,67]$.

A number of ELISAs and other antibody-based assays have also been described with detection limits in the low $\mathrm{pg} / \mathrm{ml}$ range $[11,12,62,68-74]$. The most sensitive of these combine high affinity antibodies with an extremely sensitive platform, and in many cases, incorporate one or multiple 
amplification steps $[9,10,12,62,71,73,74]$. Several of these also utilize liposomes for signal enhancement, either as scaffolds for fluorophores or as a means of encapsulating signal generating elements [75-78]. A recent report [79] describes immunoPCR using encapsulated PCR templates, with sub-fg/ml detection limits. As the AMPs tested here have similar $\mathrm{K}_{d} \mathrm{~s}$ to the antibodies used in many of these studies, we anticipate that with suitable modifications, AMP-based assays can be integrated into these alternative platforms, with appropriate improvements in sensitivity. Incorporation of AMPs into tests utilizing liposomes must, however, proceed with great care to avoid interference or disruption of the signal-generating element by the AMP $[79,80]$.

In conclusion, this is the first demonstration that the same array of semi-selective AMPs used to detect bacterial, fungal, rickettsial, and viral targets can also be used to detect analytes that do not possess membranous structures and are presumably not their natural targets. Similar to the bacterial targets, differences in the patterns of toxoid binding were demonstrated and may potentially be used for target identification. Although the present study required a tracer antibody for sandwich assays, it is the goal of future AMP-based systems to eliminate target-specific elements. If used as a complementary method to immunoassays, AMP-based tests can potentially detect a wider variety of targets, and as demonstrated in the present study, may significantly shorten the time required for results; direct binding was detectable after only 3 min (Fig. 4c); similarly short binding times for toxoids A and B were also observed. Ultimately, studies with native toxins in BL3 facilities will be required to validate the binding interactions observed in this study and to further elucidate the mechanisms involved. If those studies confirm the present work, AMPs show potential for insertion into multi-analyte assay systems as a recognition molecule complementary to antibodies.

\section{Experimental Section}

Antibodies, antigens and peptides.

The US Naval Research Laboratory is not equipped to handle the highly toxic botulinum toxins and therefore, inactivated C. botulinum type A, B, and E complex toxoids were purchased from the US Department of Defense Critical Reagents Program (CRP, Edgewood, MD); these preparations were certified inactive prior to shipment. Specific activities of the toxin complexes used to prepare the toxoids $\left(\mathrm{LD}_{50} / \mathrm{ml}\right)$ were determined by the manufacturer (Metabiologics, Inc., Madison, WI) and ranged from $1.4 \times 10^{7}$ to $3.6 \times 10^{7} \mathrm{LD}_{50} / \mathrm{mg}$, depending on the toxoid and lot. Rabbit anti-botulinum toxin A/B antibody was also obtained from CRP and cross-reacts with both the native and the toxoided forms of botulinum toxin; the extreme toxicity of the native toxins precludes their use during immunization, and thus, toxoided forms are the most common immunogens. Polymyxins B and E, polymyxin B nonapeptide, and buforin-II were obtained from Sigma-Aldrich (St. Louis, MO), cecropins A and B from Anaspec (San Jose, CA), and melittin, bactenecin, and parasin from American Peptides (Sunnyvale, CA). Stock solutions of peptides were prepared in phosphate-buffered saline (PBS), $\mathrm{pH} 7.4$, and kept refrigerated until use.

"Tracer" anti-botulinum toxin $\mathrm{A} / \mathrm{B}$ antibodies were labeled with $\mathrm{Cy} 3$ bis-reactive Nhydroxysuccinimidyl ester (GE Healthcare Life Sciences, Piscataway, NJ) as described in detail elsewhere [17]. The dye-to-protein ratios (mole/mole) ranged from 2 to 4. 


\section{Preparation of fluorescently-labeled inactivated toxins for kinetic experiments}

Inactivated botulinum toxins $\mathrm{A}, \mathrm{B}$, and $\mathrm{E}(500 \mu \mathrm{L}, 1 \mathrm{mg} / \mathrm{ml})$ were incubated for $30 \mathrm{~min}$ in $50 \mathrm{mM}$ sodium borate, $\mathrm{pH} 8.5$, with $\mathrm{Cy} 5$ bisfunctional N-hydroxysuccinimidyl ester (GE Healthcare) dissolved in $25 \mu \mathrm{L}$ anhydrous DMSO immediately before use. Following separation from unincorporated dye by gel filtration, labeled toxoids were concentrated using Centricon ${ }^{\circledR}$ centrifugal filter units (Millipore, Billerica, MA) and subsequently incubated overnight with 1 packet of Cy5maleimide (GE Healthcare). Labeled targets were then separated from free dye as above. Sequential labeling of both amino and thiol moieties allowed dye-to-protein ratios of 1.5 to 2 to be achieved. Labeled toxoids were stored in the dark at $4^{\circ} \mathrm{C}$ until use.

\section{Preparation and patterning of sensor substrates}

Conventional glass microscope slides (Daigger, Wheeling, IL) were patterned with immobilized AMPs and control antibodies using direct covalent coupling chemistry and poly(dimethy)siloxane (PDMS) patterning templates as described previously [17]; patterned slides were blocked with 10 $\mathrm{mg} / \mathrm{ml}$ gelatin, dried, and stored at $4^{\circ} \mathrm{C}$ for up to 2 weeks. Negative controls consisted of lanes patterned with buffer only, whereas positive controls were patterned with anti-botulinum toxin $\mathrm{A} / \mathrm{B}$ antibodies $(10 \mu \mathrm{g} / \mathrm{ml})$. This method results in an array of stripes oriented along the short $(25 \mathrm{~mm})$ axis of the slide, with a different recognition molecule immobilized within each striped area. After patterning, slides were blocked with a $1 \mathrm{mg} / \mathrm{ml}$ gelatin solution in PBS for at least $40 \mathrm{~min}$ and were stored dry at $4^{\circ} \mathrm{C}$ until use.

\section{Sandwich assays}

Binding assays were performed essentially as described for detection of bacterial targets using immobilized AMPs [17]. Briefly, patterned slides were incubated with $0.1 \mathrm{~mL}$ toxoid solution for 1 hour, rinsed in PBS containing $1 \mathrm{mg} / \mathrm{ml}$ BSA and 0.05\% Tween-20 (PBSTB), and then incubated, under flow, with Cy3-labeled tracer antibody $(0.4 \mathrm{~mL}$ of $10 \mu \mathrm{g} / \mathrm{ml} \mathrm{Cy3-antibody} \mathrm{in} \mathrm{PBSTB,} \mathrm{flow} \mathrm{rate}$ of $0.3 \mathrm{ml} / \mathrm{min}$ ). After a final rinse, slides were then imaged with a Packard ScanArray Lite confocal microarray scanner (Packard Biochip Technologies, Billerica, MA). The assays therefore took approximately $75 \mathrm{~min}$ and required no specialized equipment except a standard microarray scanner and a multi-channel peristaltic pump.

Fluorescence intensities were extracted from the images using QuantArray microarray analysis software Program (Packard). Concentration-dependence curves were fitted to a 3-parameter exponential rise to a maximum function (Sigma Plot software, Version 8.0, Chicago, IL). Detection limits (LODs) were calculated as lowest concentrations tested with mean net signals ( $\mathrm{n} \geq 3$ separate array elements) at least 3 standard deviations (SD) above the mean of negative control values.

\section{Binding kinetics assays}

Kinetic measurements were made using the NRL Array Biosensor essentially as previously described [81], with the assay unit mounted above an imaging system to measure surface binding events in real time. After an initial wash of each lane with PBS, different concentrations of Cy5- 
labeled toxoid (diluted in PBSTB) were injected into each channel and incubated without flow ("static"). Binding of labeled toxoids to AMPs was monitored for $2 \mathrm{~h}$. Digital images (in Flexible Image Transport System format) were collected every min for the first $10 \mathrm{~min}$, at $15 \mathrm{~min}$ and $20 \mathrm{~min}$, and finally at 20-min increments for an additional $140 \mathrm{~min}$. Fluorescent intensities were extracted from the images using a custom analysis program written in LabWindows and both specific and nonspecific (background) signals were determined [81].

Kinetic constants were determined by fitting the intensity data to the following curve:

$$
y=a\left(1-e^{-(\text {Kapp }) x}\right)
$$

where $\mathrm{y}$ indicates the intensity measured at time $\mathrm{t}$, and $\mathrm{x}$ indicates the time allowed for interaction. For each interaction, the equation was solved for $\mathrm{K}_{\mathrm{app}}$, the apparent rate constant. The rate constants were then determined from a plot of $\mathrm{K}_{\mathrm{app}}$ versus the toxoid concentration (C), where

$$
\mathrm{K}_{\mathrm{app}}=\mathrm{k}_{\mathrm{off}}+\mathrm{k}_{\mathrm{on}} \mathrm{C} \text {, }
$$

and the dissociation constant, $\mathrm{K}_{\mathrm{d}}$, was then determined as the ratio of $\mathrm{k}_{\mathrm{off}} / \mathrm{k}_{\mathrm{on}}$.

\section{Acknowledgements}

N.V.K. is recipient of a National Research Council fellowship. The authors thank the National Institutes of Health (R01 EB00680) and JSTO-CBD for their financial support. The views expressed herein are those of the authors and do not represent those of the US Navy, the US Department of Defense, or the US government.

\section{References and Notes}

1. Wein, L.M.; Liu, Y. Analyzing a bioterror attack on the food supply: The case of botulinum toxin in milk. Proc. Natl. Acad. Sci. USA 2005, 102, 9984-9989.

2. CDC. Botulism in the United States 1899-1996: Handbook for Epidemiologists, Clinicians, and Laboratory Workers; Centers for Disease Control and Prevention: Atlanta, GA, 1998.

3. Tacket, O.; Shandera, W.X.; Mann, J.M.; Hargrett, N.T.; Blake, P.A. Equine antitoxin use and other factors that predict outcome in type A foodborne botulism. Am. J. Med. 1984, 76, 794-798.

4. Falkenrath, R.A.; Newman, R.D.; Thayer, B.A. Americas's Achilles Heel. Nuclear, Biological and Chemical Terrorism and Covert Attack; MIT Press: Cambridge, MA, 1998.

5. Gill, M.D. Bacterial toxins: a table of lethal amounts. Microbiol Rev. 1982, 46, 86-94.

6. National Institute of Occupational Safety and Health. Registry of Toxic Effects of Chemical Substances (R-TECS). National Institute of Occupational Safety and Health: Cincinnati, Ohio, 1996.

7. Schantz, E.J.; Johnson, E.A. Properties and use of botulinum toxin and other microbial neurotoxins in medicine. Microbiol Rev. 1992, 56, 80-99. 
8. Centers for Disease Control and Prevention. Botulism in the United States 1899-1996: Handbook for Epidemiologists, Clinicians, and Laboratory Workers. Centers for Disease Control and Prevention: Atlanta, Ga, 1998. http://www.cdc.gov/ncidod/dbmd/diseaseinfo/botulism.pdf.

9. Salomon, H.M.; Lilly, T. Jr. In Bacteriological Analytical Manual Online, http://www.cfsan.fda.gov/3bam/bam-17.htm\#authors. Accessed 17 Oct. 2007.

10. Doellgast, G.J.; Triscott, M.X.; Beard, G.A.; Bottoms, J.D.; Cheng, T.; Roh, B.H.; Roman, M.G.; Hall, P.A.; Brown, J.E. Sensitive enzyme-linked immunosorbent assay for detection of Clostridium botulinum neurotoxins $\mathrm{A}, \mathrm{B}$, and $\mathrm{E}$ using signal amplification via enzyme-linked coagulation assay. J. Clin. Microbiol. 1993, 31, 2402-2409.

11. Wictome, M.; Newton, K.; Jameson, K.; Hallis, B.; Dunnigan, P.; MacKay, E.; Clarke, S.; Taylor, R.; Gaze, J.; Foster, K.; Shone, C. Development of an in vitro bioassay for Clostridium botulinum type B neurotoxin in foods that is more sensitive than the mouse bioassay. Appl. Environ. Microbiol. 1999, 65, 3787-3792.

12. Chao, H.-Y.; Wang, Y.-C.; Tang, S.-S.; Liu, H.-W. A highly sensitive immuno-polymerase chain reaction assay for Clostridium botulinum neurotoxin type A. Toxicon 2004, 43, 27-34.

13. Boyer, A.E.; Moura, H.; Woolfitt, A.R.; Kalb, S.R.; McWilliams, L.G.; Pavlopoulos, A.; Schmidt, J.G.; Ashley, D.L.; Barr, J. R. From the mouse to the mass spectrometer: Detection and differentiation of the endoproteinase activities of botulinum neurotoxins A-G by mass spectrometry. Anal. Chem. 2005, 77, 3916-3924.

14. Liu, W.; Montana, V.; Chapman, E.R.; Mohideen, U.; Parpura, V. Botulinum toxin type B micromechanosensor. Proc. Natl. Acad. Sci. USA 2003, 100, 13621-13625.

15. Rivera, V.R.; Gamez, F.J.; Keener, W.K.; White, J.A.; Poli, M.A. Rapid detection of Clostridium botulinum toxins A, B, E, and F in clinical samples, selected food matrices, and buffer using paramagnetic bead-based electrochemiluminescence detection. Anal. Biochem. 2006, 353, 248256.

16. Kulagina, N.V.; Lassman, M.E.; Ligler, F.S.; Taitt, C.R. Antimicrobial peptides for detection of bacteria in biosensor assays. Anal. Chem. 2005, 77, 6504-6408.

17. Kulagina, N.V.; Shaffer, K.S.; Anderson G.W.; Ligler, F.S.; Taitt, C.R. Antimicrobial peptidebased array for Escherichia coli and Salmonella screening. Anal. Chim. Acta 2006, 575, 9-15.

18. Kulagina, N. K.; Shaffer, K. M.; Ligler, F. S.; Taitt, C. R. Antimicrobial peptides, new recognition molecules for challenging targets. Sens. Actuators B 2007, 121, 150-157.

19. Hancock, R.E.W.; Chapple, D.S. Peptide antibiotics. Antimicrob. Agents Chemother. 1999, 43, 1317-1323.

20. Matsuzaki, K. Why and how are peptide-lipid interactions utilized for self defence? Biochem. Soc. Trans. 2001, 29, 598-601.

21. Papo, N.; Shai, Y. Exploring peptide membrane interaction using surface plasmon resonance: differentiation between pore formation versus membrane disruption by lytic peptides. Biochemistry 2003, 42, 458-466.

22. Andreu, D.; Rivas, L. 1999. Animal antimicrobial peptides: an overview. Biopolymers 1999, 47, 415-433.

23. Cleveland, J.; Montville, T. J.; Nes, I. F., Chikindas, M. L. Bacteriocins: safe natural antimicrobials for food preservation. J. Food Microbiol. 2001, 71, 1-20. 
24. Garcia, G.E.; Moorad, D.R.; Gordon, R.K. Buforin I, a natural peptide, inhibits botulinum neurotoxin B activity in vitro. J. Appl. Toxicol. 1999,19, S19-S22.

25. Garcia, G.E.; Gordon, R.K.; Moorad, D.R.; Doctor, B.P. Buforin I as a specific inhibitor and therpeutic agent for botulinum toxin B and tetanus neurotoxins. US Patent No. 6,713,444. 2004.

26. Gordon, R.K.; Moorad, D.R.; Doctor, B.P.; Garcia, G.E. Previns as specific inhibitors and therapeutic agents for botulinum toxin B and tetanus neurotoxins. US Patent No. 7,235,521. 2007.

27. Rowe-Taitt, C.R.; Golden, J.P.; Feldstein, M.J.; Gras, J.J.; Hoffman, K.E.; Ligler, F.S. Array biosensor for detection of biohazards. Biosens. Bioelectron. 2000, 14, 785-794.

28. Sapsford, K.E.; Taitt, C.R; Loo, N.; Ligler, F.S. Biosensor detection of botulinum toxoid A and staphylococcal enterotoxin B in food. Appl. Environ. Microb. 2005, 71, 5590-5592.

29. Cruciani, R.A.; Barker, J.L.; Zasloff, M.; Chen, H.-C.; Colamonici, O. Antibiotic magainins exert cytolytic activity against transformed cell lines through channel formation. Proc. Natl. Acad. Sci. USA 1991, 88, 3792-3796.

30. Bechinger, B.; Zasloff, M.; Opella, S.J. Structure and orientation of the antibiotic peptide magainin in membranes by solid-state nuclear magnetic resonance spectroscopy Prot. Sci. 1993, 2, 2077-2084.

31. Matsuzaki, K.; Mitani, Y.; Akada, K.; Murase, O.; Yaneyama, S.; Zasloff, M.; Miyajima, K. Mechanism of synergism between antimicrobial peptides magainin 2 and PGLa. Biochemistry 1998, 37, 15144-15153.

32. Matsuzaki, K. Why and how are peptide-lipid interactions utilized for self-defense? Magainins and tachyplesins as archetypes. Biochim. Biophys. Acta 1999, 1462, 1-10

33. Franciosa, G.; Fenicia, L.; Pourshaban, M.; Aureli, P. Recovery of a strain of Clostridium botulinum producing both neurotoxin A and neurotoxin B from canned macrobiotic food. Appl. Environ. Microbiol. 1997, 63, 1148-1150.

34. Kirma, N.; Ferreira, J.L.; Baumstark, B.R. Characterization of six type A strains of Clostridium botulinum that contain type B toxin gene sequences. FEMS Microbiol. Lett. 2004, 231, 159-164.

35. Lindström, M.; Korkeala, H. Laboratory diagnostics of botulism. Clin. Microbiol. Rev. 2006, 19, 298-314.

36. Schmidt, J. J.; Stafford, R. G.; Bostian, K. A. Type A botulinum neurotoxin proteolytic activity: development of competitive inhibitors and implications for substrate specificity at the S1' binding subsite. FEBS Lett. 1998, 435, 61-64.

37. Schmidt, J. J.; Stafford, R. G. A high-affinity competitive inhibitor of type A botulinum neurotoxin protease activity. FEBS Lett. 2002, 532, 423-426.

38. Oost, T.; Sukonpan, C.; Brewer, M.; Goodnough, M.; Tepp, W.; Johnson, E. A.; Rich, D. H. Design and synthesis of substrate-based inhibitors of botulinum neurotoxin type B metalloprotease. Biopolymers 2003, 71, 602-619.

39. Anne, C.; Turcaud, S; Quancard, J.; Teffo, F.; Meudal, H.; Fournie-Zaluski, M. C.; Roques, B. P. Development of potent inhibitors of botulinum neurotoxin type B. J. Med. Chem. 2003, 46, 46484656.

40. Sukonpan, C.; Oost, T.; Goodnough, M.; Tepp, W.; Johnson, E. A.; Rich, D. H. Synthesis of substrates and inhibitors of botulinum neurotoxin type A metalloprotease. J. Peptide Res. 2004, 63, 181-193. 
41. Schmidt, J.J.; Stafford, R.G. Botulinum neurotoxin serotype F: identification of substrate recognition requirements and development of inhibitors with low nanomolar affinity. Biochemistry 2005, 44, 4067-4073.

42. Schaivo, G.; Benfenati, F.; Poulain, B.; Rossetto, O.; Polverino de Laureto, P.; DasGupta, B. R.; Montecucco, C. Tetanus and botulinum-B neurotoxins block neurotransmitter release by proteolytic cleavage of synaptobrevin. Nature 1992, 359, 832-835

43. Schaivo, G.; Rossetto, O.; Catsicas, S.; Delaureto, P. P.; DasGeupta, B. R.; Benefenati, F.; Montecucco, C. Identification of the nerve terminal targets of botulinum neurotoxin serotypes A, D, and E. J. Biol. Chem. 1993, 268, 23784-23787.

44. Schaivo, G.; Santucci, A.; DasGupta, B. R.; Mehta, P. P.; Jones, J.; Benefenati, F.; Wilson, M. C.; Montecucco, C. Botulinum neurotoxins serotypes A and E cleave SNAP-25 at distinct COOHterminal peptide bonds. FEBS Lett. 1993, 335, 99-103.

45. Moore, G.J.; Moore, D.M.; Roy, S.S.; Hayden, L.J.; Hamilton, M.G.; Chan, N.W.C.; Lee, W.E. Hinge peptide combinatorial libraries for inhibitors of botulinum neurotoxins and saxitoxin: Deconvolution strategy. Mol. Divers. 2006, 10, 9-16.

46. Clark, G.C.; Basak, A.K.; Titball, R.W. The rational design of bacterial toxin inhibitors. Curr. Computer-Aided Drug Des. 2007, 3, 1-12.

47. Hanson, M. A.; Stevens, R. C. Cocrystal structure of synaptobrevin-II bound to botulinum neurotoxin type B at 2.0 A resolution. Nat. Struct. Biol. 2000, 7, 687-692.

48. Segelke, B.; Knapp, M.; Kankhodayan, S.; Balhorn, R.; Rupp, B. Crystal structure of Clostridium botulinum neurotoxin protease in a productbound state: Evidence for noncanonical zinc protease activity. Proc. Natl. Acad. Sci. U.S.A. 2004, 101, 6888-6893.

49. Arndt, J. W.; Chai, Q.; Christian, T.; Stevens, R. C. Structure of botulinum neurotoxin type D light chain at $1.65 \AA$ resolution - Repercussions into VAMP-2 substrate specificity. Biochemistry 2006, 45, 3255-3262.

50. Montecucco, C.; Schaivo, G. Structure and function of tetanus and botulinum neurotoxins. Quart. Rev. Biophys. 1995, 4, 423-472.

51. Breidenbach, M. A.; Brunger, A. T. Substrate recognition strategy for botulinum neurotoxin serotype A. Nature 2004, 432, 925-929.

52. Breidenbach, M. A.; Brunger, A. T. New insights into clostridial neurotoxin-SNARE interactions. Trends Mol. Med. 2005, 11, 377-381.

53. Washbourne, P.; Pellizari R.; Baldini, G.; Wilson, M. C.; Montecucco, C. Botulinum neurotoxin types A and E require the SNARE motif in SNAP-25 for proteolysis. FEBS Lett. 1997, 418, 1-5.

54. Eswaramoorthy, S.; Kumaran, D.; Swaminathan, S. Crystallographic evidence for doxorubicin binding to the receptor-binding site in Clostridium botulinum neurotoxin B. Acta Cryst. 2001, D57, 1743-1746.

55. Kitamura, M.; Sakaguchi, S.; Sakaguchi, G. Significance of $12 \mathrm{~S}$ toxin of Clostridium botulinum Type E. J. Bacteriol. 1969, 98, 1173-1178.

56. Sugii, S.; Ohishi, I.; Sakaguchi, G. Correlation between oral toxicity and in vitro stability of Clostridium botulinum type A and B toxins of different molecular sizes. Infect. Immunol. 1977, 16, 910-914.

57. Sakaguchi, G. Clostridium botulinum toxins. Pharmac. Ther. 1983, 19, 165-194. 
58. Ogert, R. A.; Brown, J. E.; Singh, B. R.; Shriver-Lake, L. C., Ligler, F. S. Detection of Clostridium botulinum toxin A using a fiber optic-based biosensor. Anal. Biochem. 1992, 205, 306-312.

59. Kumar, P.; Colston, J. T.; Chambers, J. P.; Rael, E. D.; Valdes, J. J. Detection of botulinum toxin using an evanescent wave immunosensor. Biosens. Bioelectron. 1991, 9, 57-63.

60. Singh, B. R.; Silva, M. Detection of botulinum neurotoxins using optical fiber-based biosensor. Adv. Exp. Med. Biol. 1996, 391, 499-508.

61. O'Brien, T.; Johnson, L. H. III; Aldrich, J. L.; Allen, S. G.; Liang, L.-T.; Plummer, A. L.; Krak, S. J.; Boiarski, A. A. The development of immunoassays to four biological threat agents in a bidiffractive grating biosensor. Biosens. Bioelectron. 2000, 14, 815-828.

62. Peruski, A. H.; Johnson, L. H. III; Peruski, L. F., Jr. Rapid and sensitive detection of biological warfare agents using time-resolved fluorescence assays. J. Immunol. Methods 2002, 263, 35-41.

63. Sharma, S. K.; Eblen, B. S.; Bull, R. L.; Burr, D. H.; Whiting, R. C. Evaluation of lateral-flow Clostridium botulinum neurotoxin detection kits for food analysis. Appl. Environ. Microbiol. 2005, 71, 3935-3941.

64. Urbanowicz, R. Reassessment of a ganglioside-liposome biosensor; M. Eng. Thesis, Cornell Univ.: Ithaca, NY, 2005.

65. Barr, J. R.; Moura, H.; Boyer, A. E.; Woolfitt, A. R.; Kalb, S. R.; Pavlopoulos, A.; McWilliams, L. G.; Schmidt, J. G.; Martinez, R. A.; Ashley D. L. Botulinum neurotoxin detection and differentiation by mass spectrometry. Emerg. Infect. Dis. 2005, 11, 1578-1583.

66. Schmidt, J.J.; Stafford, R.G.; Millard, C.B. High-throughput assays for botulinum neurotoxin proteolytic activity: serotypes A, B, D, and F. Anal. Biochem. 2001, 296, 130-137

67. Hancock, R.E.W.; Sahn, H.-G. Antimicrobial and host-defense peptides as new anti-infective therapeutic strategies. Nature Biotechnol. 2006, 24, 1551-1557.

68. Sharma, S. K.; Ferreira, J. L.; Eblen, B. S.; Whiting, R. C. Detection of type A, B, E, and F Clostridium botulinum neurotoxins in foods by using an amplified enzyme-linked immunosorbent assay with digoxigenin-labeled antibodies. Appl. Environ. Microbiol. 2006, 72, 1231-1238.

69. Fach, P.; Perelle, S.; Dilassar, F.; Grout, J.; Dargaignaratz, C.; Botella, L.; Gorreau, J.M.; Carlin, F.; Popoff, M.R.; Brousalle, V. Detection by PCR-enzyme-linked immunosorbent assay of Clostridium botulinum in fish and environmental samples from a coastal area in northern France. Appl. Environ. Microbiol. 2002, 68, 5870-5876.

70. Poli, M.A.; Rivera, V.R.; Neal, D. Development of sensitive colorimetric capture ELISAs for Clostridium botulinum neurotoxin serotypes E and F. Toxicon 2002, 40, 797-802.

71. Ferreira, J.L.; Maslanka, S.; Johnson, E.; Goodnough, M. Detection of preformed type A botulinal toxin in hash brown potatoes by using the mouse bioasssay and a modified ELISA test. $J$. AOAC 2003, 84, 1460-1464.

72. Ma, H.; Zhou, B.; Kim, Y.S.; Jana, K.D. A cyclic peptide-polymer probe for the detection of Clostridium botulinum neurotoxin serotype A. Toxicon 2006, 47, 901-908.

73. Shone, C.; Wilton-Smith, P.; Appleton, N.; Hambleton, P.; Modi, N.; Gatley, S.; Melling, J. Monoclonal antibody-based immunoassay for type A Clostridium botulinum toxin is comparable to the mouse bioassay. Appl. Environ. Microbiol. 1985, 50, 63-67. 
74. Ekong, T. A. N.; McLellan, K.; Sesardic, D. Immunological detection of Clostridium botulinum toxin type A in therapeutic preparations. J. Immunol. Methods 1995, 180, 181-191.

75. Singh, A.K.; Harrison, S.H.; Schoninger, J.S. Gangliosides as receptors for biological toxins: Development of sensitive fluoroimmunoassays using ganglioside-bearing liposomes. Anal. Chem. 2000, 72, 6019-6024.

76. Ahn-Yoon, S.; DeCrory, T.R.; Durst, R.A. Ganglioside-lipsosome immunoassay for the detection of botulinum toxin. Anal. Bioanal. Chem. 2004, 378, 68-75.

77. Wu, H.C.; Huang, Y.L.; Lai, S.C.; Huang, Y.Y.; Shaio, M.F. Detection of Clostridium botulinum neurotoxin type A using immuno-PCR. Lett. Appl. Microbiol. 2001, 32, 321-325.

78. Chao, H.-Y.; Wang, Y.-C.; Tang, S.-S.; Liu, H.W. A highly sensitive immuno-polymerase chain reaction assay for Clostridium botulinum neurotoxin type A. Toxicon 2004, 43, 27-34.

79. Mason, J.T.; Xu, L.; Sheng, Z.-M.; O'Leary, T.J. A liposome-PCR assay for the ultrasensitive detection of biological toxins. Nature Biotechnol. 2006, 24, 555-557.

80. Edwards, K.A.; Baeumner, A.J. Analysis of liposomes. Talanta 2006, 68, 1432-1441.

81. Ngundi, M. M.; Taitt, C. R.; Ligler, F. S. Simultaneous determination of kinetic parameters for the binding of cholera toxin to immobilized sialic acid and monoclonal antibody using an array biosensor. Biosens. Bioelectron. 2006, 22, 124-130.

(C) 2007 by MDPI (http://www.mdpi.org). Reproduction is permitted for noncommercial purposes. 